\title{
Vestigios góticos en la literatura arquitectónica del barroco
}

\author{
Emilio Morais Vallejo \\ Universidad de León
}

RESUMEN:

Durante la época del barroco un número importante de arquitectos utilizaron formas góticas en sus edificios. Esta práctica tiene su correlación con la teoría arquitectónica, de manera que encontramos en ese período histórico interesantes textos científicos, técnicos, literarios o simplemente descriptivos que explican, aprueban, invocan o enseñan a realizar estructuras góticas. En este artículo hacemos un recorrido por los más importantes escritos españoles que trataron el tema con el fin comprender mejor su significado en el contexto de la arquitectura barroca.

PALABRAS CLAVE:

Arquitectura Barroco-gótica, Tratados de arquitectura, Literatura artística.

ABSTRACT:

During the Baroque period, a considerable number of architects employed Gothic forms in their buildings. This practice was paralleled in architectural theory, and thus this historical period produced interesting scientific, technical, literary or simply descriptive texts which explained, approved, solicited or taught the construction of Gothic structures. The present article provides an overview of the most important Spanish texts which addressed the topic, in order to gain a better understanding of their significance in the context of Baroque architecture.

KEY WORDS:

Baroque-gothic architecture, Architectural treatises, Artistic literature. 
La arquitectura española siguió utilizando formas heredadas del tardogótico durante toda la época del Barroco, e incluso se puede hablar de una puntual revitalización en algunos momentos y en ciertos ambientes culturales cercanos a las élites del poder. Esto fue posible porque determinados arquitectos y maestros de obra, apoyados o animados por promotores que veían su gusto mejor plasmado en fórmulas tradicionales, las seguían considerando válidas para sus propuestas. Encontramos diferencias en la cantidad de muestras existentes según las zonas geográficas o la cronología, pero, en cualquier caso, resulta evidente el vigor de esta pervivencia que contradice el discurso cronológico oficial de los periodos artísticos. De hecho, por toda España, al igual que en el resto de Europa, podemos hallar testimonios de esta supuesta disfunción estilística, considerada como una anomalía si nos atenemos a los criterios generales que hemos establecido los historiadores del Arte para facilitar nuestra tarea. Los ejemplos tendrán mayor o menor calidad arquitectónica, pero siempre resultan interesantes para comprender más certeramente la historia de la arquitectura ${ }^{1}$.

Desde el artículo de J. Ma. AZCARATE, "La valoración del gótico en la estética del siglo XVIII", Cuadernos de la Cátedra Feijóo, no 18, 1966, p. 525-549, la bibliografía española que estudia tan singular actuación ha ido poco a poco en aumento. Véase por ejemplo: BARRIO LOZA, J.A. y MOYA VALGAÑÓN, J.G., "El modo vasco de producción arquitectónica en los siglos XVI-XVII", Kobie, $\mathrm{n}^{\circ}$ 10, 1980, pp. 283-369; RUIZ HERNANDO, J.A., "Pervivencia de la arquitectura y urbanismo góticos en Segovia. Estado de la cuestión”, en Arte Gótico postmedieval: actas del Simposio Nacional del Comité Español de Historia del Arte, 1985, pp. 37-46; MONTOLIU SOLER, V., "Mantenimiento de las estructuras góticas en la arquitectura barroca valenciana”, en Simposio Nacional del C.E.H.A. Arte gótico postmedieval, Segovia, 1987, pp. 179-185; FALCÓN MÁRQUEZ, T., "Un edificio gótico fuera de época. La prioral de El Puerto de Santa María”, Laboratorio de Arte, Sevilla, 1992, n 5, tomo I, pp. 205-222; RAMALLO ASENSIO, G., "Recurrencias a la estética tardogótica en la arquitectura asturiana del primer tercio del XVIII" Anales de la Historia del Arte. Madrid, no 4, 1994, pp. 225-236; COFIÑO FERNÁNDEZ, I., "Las recuperaciones historicistas en la arquitectura religiosa del barroco castellano", en Edades, Revista de Historia, nº 2, 1997, pp. 113-122; ÍDEM, "La actividad de los talleres y maestros montañeses en las Encartaciones durante el Barroco: pervivencia del Gótico y del Clasicismo", Letras de Deusto, vol. 32, n 97, 2002, págs. 123-152; GÓMEZ MARTÍNEZ, J., El gótico español de la Edad Moderna: bóvedas de crucería, Valladolid, 1998; POMAR RODIL, P., "Arquitectura barroca de progenie gótica en España e Hispanoamérica", en III Congreso Internacional
La práctica constructiva no siempre va acompañada de un respaldo teórico, máxime si las realizaciones, como es el caso que nos ocupa, no siguen las propuestas vanguardistas que suelen ser motivo esencial de la literatura artística de cada momento. Tampoco suele interesar el estudio especulativo de formas ya superadas por el gusto predominante, prefiriendo resaltar las novedades que se tratan de imponer en busca de un nuevo estilo. Los autores renacentistas ya habían auspiciado una ruptura total con la Edad Media, considerada abyecta para el desarrollo del arte, con el fin de imponer cuanto antes la recuperación de lo antiguo (clásico), frente a lo moderno (gótico); por eso, prácticamente no aparecen menciones al medievo en los textos especializados, y cuando lo hacen es con clara intención peyorativa. Con la llegada del barroco comienza una tímida reivindicación de la arquitectura gótica, que tendrá su momento de gloria más adelante con la irrupción de los neos. No obstante, los teóricos de los siglos XVII y XVIII, por lo general, fueron poco proclives a reconocerla méritos; la mayoría optó por ignorarla, mientras que otros la trataron despectivamente, como obra propia de bárbaros ${ }^{2}$. Sin embargo, un destacado elenco de autores europeos entendió que las formas medievales podían incluirse sin rubor en sus esquemas teóricos o en sus realizaciones. Así, encontramos un relevante número de textos científicos y técnicos que se ocuparon de las

del Barroco Iberoamericano, Sevilla, 2001, pp. 1.1091.122; ÍDEM, "La pervivencia de la técnica medieval en la arquitectura andaluza: la catedral de Jerez de la Frontera (Cádiz), una construcción "gótica» del pleno barroco" Actas del III congreso nacional de historia de la construcción, Sevilla, 2000, t. II, pp. 841-851; RÍOS MARTÍNEZ, E., "Gótico, barroco y romántico en la arquitectura jerezana del siglo XVIII”, Revista de Historia de Jerez, 2001, pp. 127-135; ÍDEM, “Antón Martín Calafate, iniciador de la reactivación del gótico en la provincia de Cádiz, a través de la reedificación de la iglesia prioral de El Puerto de Santa María en el siglo XVII", Laboratorio de Arte, no 22, 2010, pp. 165-184; GARCÍA DEL BUSTO, 0., "La continuidad de las formas góticas en el siglo XVII asturiano. La reforma de la iglesia parroquial de San Nicolás de Bari en Avilés", Liño, 2010, $n^{\circ} 16$, pp. 21-32; MORAIS VALLEJO, E., "Pervivencia de formas góticas en la arquitectura del barroco. El caso de León", Boletín del Museo e Instituto Camón Aznar, 2011, no 108, pp. 195-242; ÍDEM, "Formas góticas en la arquitectura del Barroco de la provincia de Burgos", BSAA Arte, 2013, nº. 79, pp. 117-142.

2 Véase algunos ejemplos de esta opinión en PATETTA, L., Historia de la arquitectura. Antología crítica, Madrid, 1997, pp. 180-183 
formas góticas, lo que demuestra la superación de los prejuicios renacentistas y clasicistas sobre aquella arquitectura, que actuó en paralelo con el interés práctico de señalados artífices. No obstante, señalamos que esta pervivencia es más formal que estructural, pues hay un cierto olvido del sistema propio de la bóveda de crucería $^{3}$, atendiendo más al léxico, la molduración y la composición que al aspecto científico de la edificación, que con frecuencia queda relegado a un segundo plano ${ }^{4}$.

En Italia, donde el gótico no tuvo la extensión o vigencia de otros países europeos, hubo interesantes polémicas sobre la utilización de formas medievales fuera de su tiempo ${ }^{5}$, siendo las más llamativas las que motivaron la terminación de fachadas tan importantes como las de la catedral de Milán o San Petronio de Bolonia. También algunos teóricos se preocuparon por analizar el tema desde una mentalidad canónica, e incluso llegaron a utilizar algunos de sus elementos en edificaciones propias. Es el caso de Guarino Guarini, impresionado por el mundo medieval, quien recogió de aquí algunas ideas que resultaron fructiferas para sus teorías y también, como es notorio, para sus peculiares realizaciones. Al parecer, tenía en alta consideración al gótico por la singularidad de sus edificios, opuestos a la solidez de los basados en los principios romanos, pues parecían mantenerse en pie de forma milagrosa gracias a ingeniosos constructores. Aunque se daba cuenta de que esa preocupación por la esbeltez y la altura les hacían desentenderse de las normas y los preceptos, creía que no por eso carecían de arte. Al igual que Caramuel, cuya teoría conocía, incluyó entre los órdenes al gótico, lo cual es demostrativo de la existencia de una simpatía hacia ese estilo dentro de determinados círculos intelectuales ${ }^{6}$. Trató de

RABASA DÍAZ, E., Forma y construcción en piedra. De la cantería medieval a la estereotomía del siglo XIX, Madrid, 2000, p. 192.

4 MARÍAS, F, "Gótico, tardogótico y neogótico en la Castilla de los siglos XV y XVI. Algunos problemas", en La arquitectura tardogótica castellana entre Europa y América, B. ALONSO RUIZ (coord.) Madrid, 2011, p. 235

5 El tema lo trataron, WITTKOWER, R., Gothic vs. Classic. Architectutural projects in seventeenth-century Italy, Nueva York, 1974; ACKERMAN, J. S., "Ars sine scientia nihil est. Gothic theory of arquitecture at the cathedral of Milan", The Arte Bulletin, vol. 31, n 2, pp. 84-111.

6 Sobre la dialéctica mantenida por estos dos autores, véase, OESCHLIN, "Bemerkungen zu Guarino Guarini encontrar una cierta reglamentación para que fuera posible hablar de un canon, insertando entre los dibujos explicativos columnas con una proporción modular de 15, 18 o incluso 20, desmesurada para lo clásico pero que para Guarino al menos respondía a una regla ${ }^{7}$. Además de aportar justificación para los alzados, incluyó en su tratado los diseños de varias bóvedas que podían servir para la crucería ${ }^{8}$, tratando en concreto la característica bóveda gótica ${ }^{9}$.

También es significativa para la época la inserción de una lámina con una arquitectura gótica en el tratado de Galli Bibiena, lo que indica interés por el medievo en un momento en el que ya se anunciaba una nueva vuelta al clasicismo $^{10}$.

En el ámbito germano sobresale en primer lugar Oseas Schadaeus, quien, al hacer una descripción de la catedral de Estrasburgo ${ }^{11}$, realiza una de las primeras guías ilustradas que estudia un edificio medieval con intención científica, otorgando así importancia a un edificio emblemático del gótico centroeuropeo ${ }^{12}$. Se sitúa de esta manera en contra de la opinión generalizada en el ámbito germano, representada por J. von Sandrat, que, a pesar de considerar al gótico como el sexto orden, arremete contra él por ser torpe, desordenado y no tener ningún tipo de proporción ${ }^{13}$.

Más tarde destaca la moderada valoración que hace Fischer von Erlach en el prólogo de su tratado ${ }^{14}$. La obra tenía entre sus propósitos mostrar diversos tipos de arquitectura con el fin de que fueran fuentes de nuevas invenciones, más allá de la autorizada clasicista, proponiendo ya un eclecticismo formal. Esta apertura hacia modelos anteriores al renacimiento o fuera

und Juan Caramuel Lobkowitz”, en Raggi, vol. 9, 1969, pp. 91-109.

7 GUARINI, G., Architettura Civile, Tratado III, capítulo XIII, Turín, 1737, pp. 133-134.

8 ÍDEM, tratado III, capítulo XXVI, pp. 184-186 y en su correspondiente gráfico en la lámina 19.

9 GARCIA JARA, F., "La representación gráfica de cúpulas en la "arquitettura civile" de Guarino Guarini”, $X$ Congreso Internacional Expresión Gráfica aplicada a la Edificación, Alicante, 2010., p. 747.

10 GALLI BIBIENA, G., L'architettura civile preparata su la geometria e ridotta alle prospettive, Parma, 1711.

${ }^{11}$ SCHADAEUS, 0., Summum Argentoratensium templum, Strasburg, 1617.

12 FRANKL, P., The Gothic. Literary sources and interpretations trough eight centuries, Princeton, 1960, p. 330.

13 SANDRAT, J. von, Teutsche Akademie, Nuremberg, 1675, p. 17.

14 FISCHER VON ERLACH, J. B., Entwurff Einer Historischen Architectur, Leipzig, 1725. 
del área occidental, se convierte en una justificación para el uso de elementos góticos en pleno siglo XVIII, afirmando que ...la costumbre autoriza ciertas bizarrias en el arte de construir, como son la tracería gótica y la bóveda de crucería con arcos apuntados ${ }^{15}$.

Algunos tratadistas del barroco francés se sintieron atraídos por el gusto gótico, cuestión que podríamos incluir dentro de una corriente generalizada en defensa de la tradición, que ciertos autores defienden en sus textos. En este sentido es revelador que Derand se ocupara en su tratado de la descripción y, lo que es más llamativo, la manera de realizar lo que él llama "bóvedas modernas o de ojivas", demostrando así su historia y actualidad ${ }^{16}$. Pero el espaldarazo definitivo puede estar en la desmitificación que hizo Claude Perrault de los órdenes clásicos, planteando la posibilidad de que los valores estéticos son una reacción del hombre, histórica y psicológicamente justificable, pero subjetiva, relativa y variable ${ }^{17}$. Esto sirvió para legitimar y descubrir bellezas arbitrarias en el gótico, apareciendo reflexiones positivas en tratadistas del XVII, como François Blondel, que encuentra allí proporciones hermosas y pone de ejemplo la fachada de la catedral de Milán, que analiza para encontrar la base geométrica de su belleza ${ }^{18}$. En el siglo siguiente J. F. Blondel estudia edificios emblemáticos del glorioso gótico francés, atendiendo incluso a detalles constructivos, porque le parecen fórmulas que pueden servir de modelo para la construcción contemporánea ${ }^{19}$.

El tratado de estereotomía de Frézier resulta interesante porque preconiza el análisis y conocimiento de las bóvedas de crucería, necesarios para la restauración de edificios antiguos ${ }^{20}$; respalda así la conservación de estructuras propias de la Edad Media o, en su caso, la sustitución

15 PANOFSKY, E., El significado de las artes visuales, Madrid, 1995, p. 203.

16 DERAND, F., L'architecture des voûtes. L'Art des traits et coupe des voutes, París, 1643, pp. 392-395.

17 PERRAULT, C., Ordonnance des cinq espèces de colonnes selon la méthode des anciens, Paris, 1683.

18 BLONDEL, F., Cours d'architecture, Paris, 1675-83, pp. 777-778.

19 BLONDEL, J. F, Architecture Françoise, Paris, 175256 ; BLONDEL, J. F, Cours d'architecture ou traité de la décoration, distribution et construction des bâtiments, Paris, 1771.

20 FRÉZIER, A. F., La théorie et la pratique de la coupe des pierres et des bois pour la construction des voutes et autres parties des bâtiments civils et militaires ou traité de stéréotomie, Estrasburg, 1737-1739. por otras realizadas conforme a su manera, pues han demostrado a lo largo del tiempo tanto belleza como durabilidad.

Por otro lado, Michel Frémin se convirtió en uno de los primeros teóricos que reconoció la importancia del gótico para el desarrollo de la arquitectura estructural ${ }^{21}$, aprobando, a la vez, una simbiosis de lo greco con lo medie$\mathrm{val}^{22}$. Pero fue el historiador Cordemoy quien propuso la fusión en un mismo edificio de las características de la construcción gótica, identificada por la ligereza de sus estructuras, con los principios estéticos del clasicismo, basados en los órdenes ${ }^{23}$, convirtiéndose de esta manera en el fundador teórico de una arquitectura que combina sin dificultad estructuras medievales con formas griegas ${ }^{24}$. Le siguió en esta apuesta Laugier $^{25}$, quien admite la audacia, el carácter majestuoso y la espacialidad del estilo, lo que le confiere belleza a pesar de lo que él considera proporciones falsas y ornamentos extravagantes ${ }^{26}$. Se abre así la posibilidad de crear formas "neogóticas", que tendrán su desarrollo en el siglo siguiente.

La particular arquitectura del gótico británico se mantuvo más viva que en el continente, no suscitando la descalificación propia de las zonas donde triunfó el renacimiento de raíz italiana $^{27}$. Los arquitectos siguieron utilizando formas góticas, siendo un buen ejemplo de dualidad Wren, que lo mismo edificaba o restauraba iglesias en su estilo medieval, que se encargaba de la clasicista catedral de S. Pablo de Londres. Prueba de este interés es el destacado papel que otorga John Aubrey a los edificios góticos en Monumenta Britannica. Lo mismo sucede con el Monasticon Anglicanum, donde

${ }^{21}$ FRAMPTON, K., Estudios sobre cultura tectónica. Poéticas de la construcción en la arquitectura de los siglos XIX y XX, Madrid, 1999, p. 39.

22 FRÉMIN, M., Mémoires critiques d'architecture contenant l'idée de la vraie et de la fausse architecture. París, 1702.

23 CORDEMOY, J. L., Nouveau traité de toute l'architecture, Paris, 1706.

24 BÁNÁT-SZ CS, M., “J. L. de Cordemoy's theory of architecture", Periodica Polytechnica Architecture, v. 30, no 1-4 (1986), pp. 9-17; MIDDLETON, “The Abbé de Cordemoy and the Graeco-Gothic Ideal: A Prelude to Romantic Classicism", Journal of the Warburg and Courtauld Institutes, vol. 25, $\mathrm{n}^{\circ}$. 3-4, 1962, pp. 278320.

25 LAUGIER, M. A., Essai sur l'architecture, París, 1753.

26 FRAMPTON, K., Op. cit, p. 39.

27 Sobre el tema, véase CLARK, K., The Gothic Revival. An Essay in the History of Taste, Londres, 1974. 
vemos un interesante repertorio de edificios medievales, aunque el libro tenga más interés histórico que constructivo ${ }^{28}$.

Distinto es el caso de Batty Langley que trató de "mejorar" las formas góticas dotándolas de proporciones semejantes a las clásicas y estableciendo una serie de reglas para que pudieran ser aceptadas por el gusto inglés de su tiempo; al mismo tiempo, hizo posible su realización en pleno siglo XVIII. Así, propone cinco órdenes góticos, quizás remedo de los cinco órdenes clásicos de Vignola, para ser utilizados en los edificios de la época ${ }^{29}$ (fig. 1).

La diversidad de propuestas vistas indica el interés teórico que había en toda Europa por los diseños góticos durante toda la época barroca, y por tanto su pervivencia y vigencia en determinados círculos intelectuales y sociales.

España no estaba al margen de esta corriente y son notorios los textos que sirvieron para prolongar la vida a estas formas más allá de su tiempo original. En primer lugar hemos de

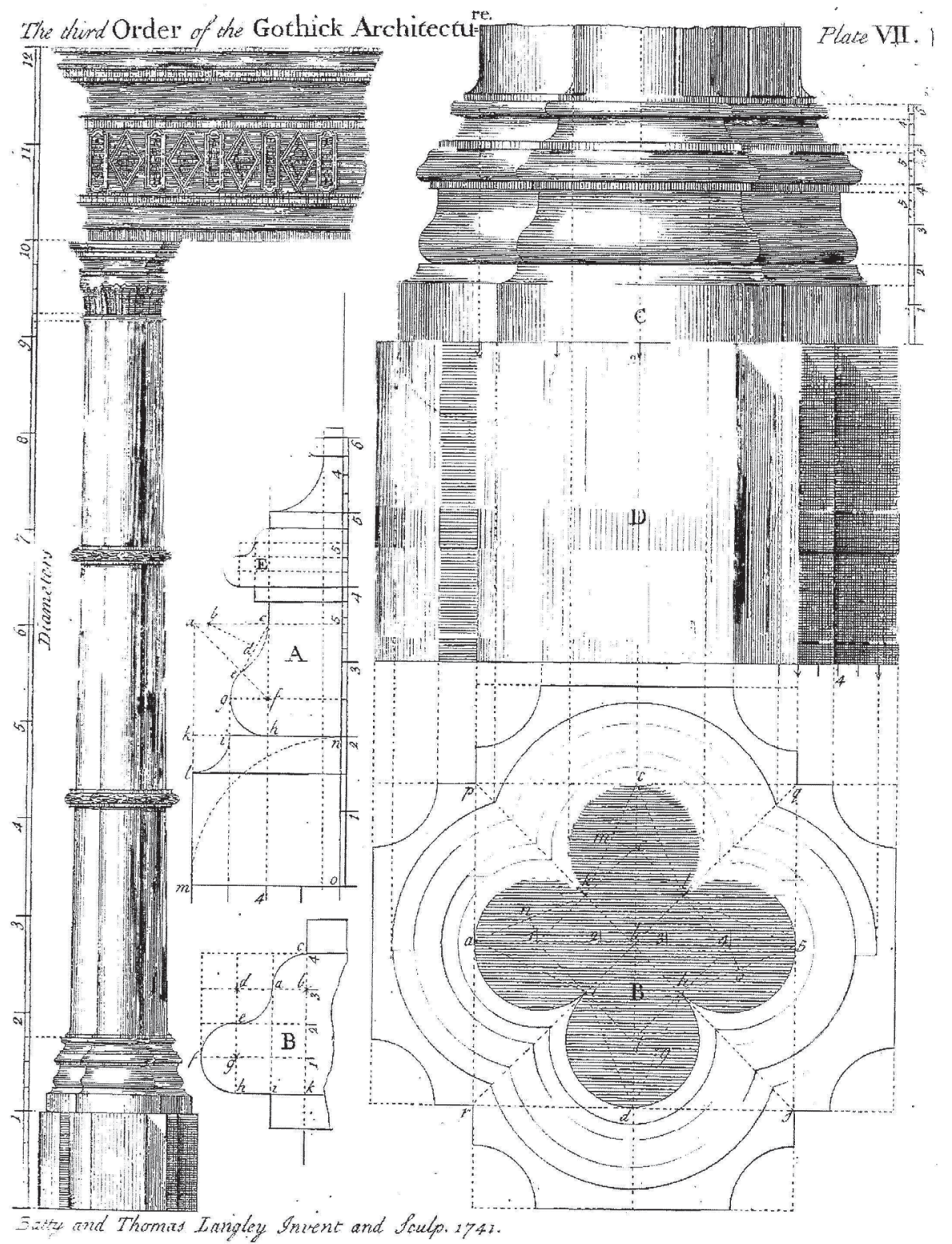

Fig. 1. El segundo orden de la arquitectura gótica, lámina IV, Gothic Architecture, improved by rules and proportions, Batty Langley.

${ }_{28}$ DUGDALE, W. y DODSWORTH, R., Monasticon Anglicanum, Londres, 1693.
$29 \quad$ LANGLEY, B., Gothic Architecture, improved by rules and proportions, Londres, 1742. 
tener en cuenta que algunos de los textos de teoría y técnica arquitectónica más importantes del siglo XVI, que incluían fórmulas góticas en su corpus, siguieron vigentes en la centuria siguiente porque los constructores continuaban utilizándolas. Entre ellos destaca el Tratado de Arquitectura de Vandelvira, que fue copiado al menos en dos ocasiones en el siglo XVII con la intención de ser publicado ${ }^{30}$, cosa que finalmente no ocurrió. Habría que añadir un manuscrito que se considera un apéndice del mismo, no concluido y de gran sentido práctico, preparado por Lázaro de Goiti, en el que aparecen dos dibujos, sin títulos ni explicaciones, con sendas bóvedas de crucería con combados ${ }^{31}$. Además de estos manuscritos habría otros cuadernos más sencillos que, lejos del interés especulativo, recogerían los aspectos de mayor sentido práctico, destinados sobre todo a los maestros de obras ${ }^{32}$.

El Compendio de Architectura de Simón García, que tiene importantes débitos con Rodrigo Gil de Hontañón, del que copió gran parte de los capítulos, se puede considerar una obra con aportaciones de ambos arquitectos que vivieron en siglos diferentes ${ }^{33}$. También aquí coexisten formulaciones clásicas al lado de dibujos de plantas tardogóticas y cubiertas de crucerías con nervios combados (fig. 2). Esta empeño por recuperar y renovar un texto antiguo solo es comprensible desde la actualidad de dichas fórmulas en pleno barroco; es evidente que si Simón García las sigue proponiendo en fecha tan avanzada es porque las consideraba útiles para los constructores

30 La primera vez en Toledo en 1646: Libro de cortes de cantería de Alonso de Vande Elvira, arquitecto, sacado a la luz y aumentado por Philipe Lázaro de Goiti, arquitecto, maestro mayor de obras de la Santa Iglesia de Toledo. La otra, probablemente de 1671: Exposición y declaración sobre el tratado de cortes de fábrica que escribió Alonso de Vandelvira por el excelente e insigne architecto y maestro de architectura don Bartolomé de Sombigo y Salcedo, Maestro Mayor de la Santa Iglesia de Toledo.

31 SUÁREZ QUEVEDO, D., "Felipe Lázaro de Goiti y sus manuscritos de cantería de la Biblioteca Nacional. Una aproximación a autor y obra en su contexto", Anales de Historia del Arte, 2002, no 12, pp. 134 y 147.

32 BARBÉ-COQUELIN, G., Tratado de arquitectura de Alonso de Vandelvira, Albacete, 1977, p. 29.

33 GARCÍA, S., Compendio de architectura y simetría de los templos conforme a la medida del cuerpo humano, 1683, ed. facsímil, Colegio Oficial de Arquitectos Valladolid, 1991, en el f. 52r. dice: "Rodrigo Gil... de quien es lo mas de este compendio por aver venido a mis manos un manuscrito suio". del momento, pues, en caso contrario las hubiera obviado en su copia. En este sentido es especialmente elocuente la explicación que hace sobre la manera de realizar una bóveda de crucería para que sea sólida y ligera, donde afırma: bemos que en las capillas que se açen de crucería... muchas que se arruinan; es decir, en este siglo XVII se están haciendo bóvedas de crucería, se fabrican mal y es necesario dar instrucciones para que se hagan de manera correcta y consistente. Además, advierte sobre la forma de trazar los arcos y la manera de construirlos, adjuntando un dibujo con diseño de combados, disposición y aspecto de las claves, junto con la explicación geométrica de todo ello. Al mismo tiempo quiere establecer una regla general para dar la debida proporción a la cubierta nervada. Para ello utiliza la consabida idea antropométrica, tan cara a los teóricos del renacimiento, como fórmula infalible de perfección y belleza. Esta vez con referencia a la mano: El dedo polus se tenga por el arco, $y$ el index $y$ el anulo por terceletes, $y$ el del medio por cruzero, y el auriculi por forma... Y de esta manera serán proporcionados; por lo tanto, formas y técnicas tardogóticas con razonamiento y ritmo renacentistas. Estaríamos ante una obra que quiere ser útil a la construcción de aquella época incluyendo caracteres medievales, pero sin olvidar los principios estéticos clasicistas del primer barroco.

El primer teórico español del barroco que amparó la categoría de un orden gótico fue Juan de Caramuel, otorgándole unos valores que hasta el momento no habían sido aceptados en la tratadística más especulativa, aunque sí en la empírica. Para introducir el orden y diferenciarlo de los otros diez anota: El octavo es el Góthico, que se usaba en las Provincias del Septentrión antiguamente; y quando sus Naturales... entraron en Italia y España... vino tambien con ellos, y revocando las leyes que la arquitectura Griega y Latina prescribia fue todo puesto en obra ${ }^{34}$. Así pues, el punto de partida para definirlo es desautorizar la supuesta validez absoluta de los principios greco-latinos, al tiempo que destaca la originalidad que supone frente a la dictadura imperante de lo clásico ${ }^{35}$.

\footnotetext{
4 CARAMUEL LOBKOWITZ, J., Architectura civil recta $y$ obliqua. Considerada y dibvxada en el Templo de Ierusalen, Vigevano, 1678, tratado V, p. 42.

35 BONET CORREA, A., Figuras, modelos e imágenes en
} los tratadistas españoles, Madrid, 1993, p. 223. 


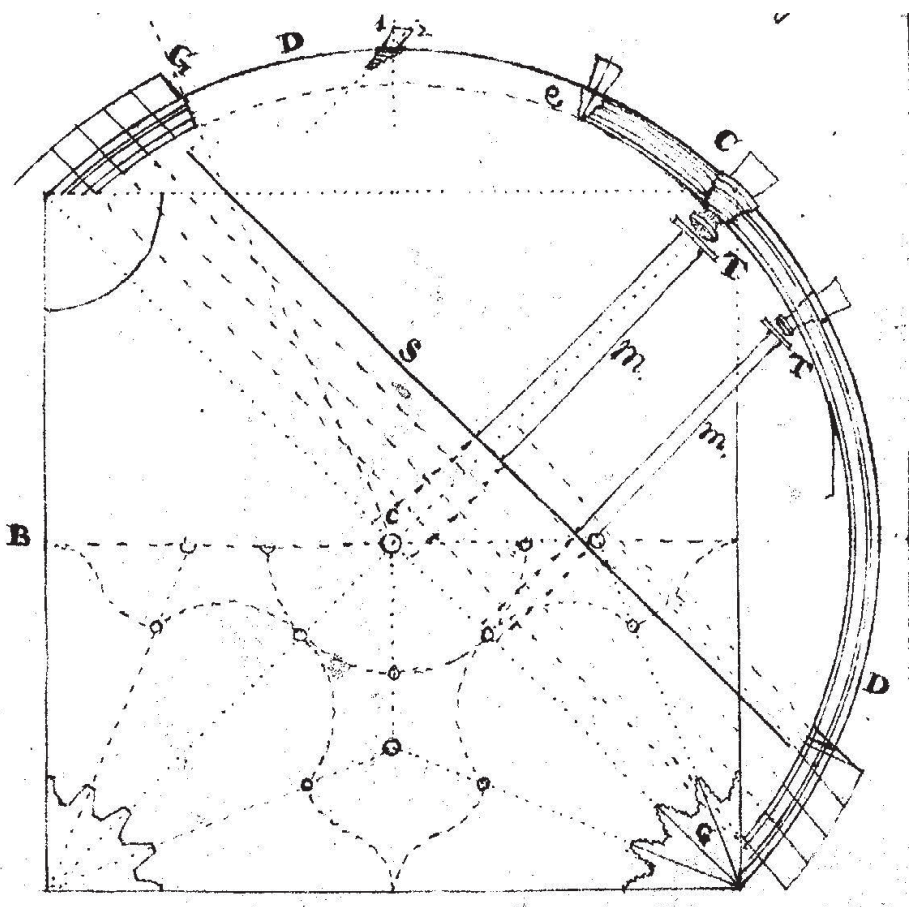

A partir de ahí encuentra que es verdaderamente curiosa y ingeniosa la Gothica; y dificultosa si se ha de labrar bien, fijando sus principales valores en la dificultad constructiva de sus complejas estructuras y en la sorprendente capacidad imaginativa desplegada por los arquitectos para diseñar edificios con semejantes osadías $^{36}$. Esta simpatía también se puede explicar dentro de su ideario, sobre todo si consideramos la utilización de esas formas como una manera más de subvertir las normas clásicas, de romper con lo canónico abriendo posibilidades a la libertad compositiva, definitoria en sí misma de la arquitectura barroca defendida por Caramuel. Con esta acción está amparando la originalidad de una serie de modelos estéticos que hasta entonces habían sido tenidos como bárbaros, y que sin embargo él afirma que tienen sus propias virtudes que han de ser descubiertas con una mirada sin prejuicios: ...assi los Judios y los Godos cortaron o dibuxaron muchas piedras sin haver visto semejantes ideas en griegos y romanos alcazares ${ }^{37}$. Está en contra de la dictadura clasicista dominante hasta el momento, sosteniendo que en muchos lugares se levantaron edificios admirables sin conocer previamente los grecorromanos y sus reglas, así que también sería válida la utilización del

36 CARAMUEL LOBKOWITZ, J., Op. cit., Tratado V, p. 74. 37 IBÍDEM. p. 43. rico acervo medieval ${ }^{38}$. Para Caramuel no existen reglas absolutas; por lo tanto el arquitecto está autorizado a utilizar un repertorio personal más allá del permitido por la arquitectura canónica $^{39}$, entrando aquí el permiso para emplear formas tardogóticas. Tampoco debemos olvidar que cuando habla del octavo orden no se refiere sólo a un estilo pretérito, sino también a un modo de construir vigente. Tanto es así, que por aquellos años surgió en Italia una interesante polémica sobre la convivencia de estilos distintos en un mismo edificio, como sucedió con importantes proyectos para cerrar construcciones inconclusas ${ }^{40}$.

También queremos dejar constancia del reconocimiento que hace de la estereotomía gótica ...que para ser bien executada, pide que con gran ingenio, y no sin gran cuydado y advertencia se proceda en sus cortes ${ }^{41}$. Considera que se necesita una gran capacidad técnica para llevar a buen término esas sorprendentes y complicadas estructuras, lo cual es muy meritorio, digno de encomio y que además resulta agradable a la vista.

38 FERNÁNDEZ-SANTOS, J., Juan Caramuel y la probable arquitectura, Madrid, 2014, p. 318.

39 BONET CORREA, A., Estudio preliminar del facsímil Arquitectura civil recta y oblicua, p. XXVII.

40 Esta cuestión la platea PENA BUJÁN, C., "La arquitectura de los bárbaros: Juan de Caramuel de Lobkowitz y el orden gótico", Quintana, n 4, pp. 197-212.

41 CARAMUEL LOBKOWITZ, J., Op. cit., Tratado V, p. 74. 
De cualquier manera, le parece difícil conceder el calificativo de bella a la arquitectura gótica, ya que ...después de bien executada y trabajada, no es hermosa, aunque a la vista de los juegos de los soportes y los volúmenes característicos del estilo ...se divierten los ojos con una proporcionada variedad, señalando de esta manera la categoría de la variedad, el resultado pintoresco en el sentido estético del término, como elemento determinante del gusto gótico. Quizás fuera este argumento el que le permite elogiar las bóvedas de crucería, que le parecen difíciles de fabricar, afirmando que ...no solamente en las colunas, sino tambien en las vovedas tuvieron los Godos muy especial Architectura ${ }^{42}$.

Para respaldar sus halagos recurre Caramuel al libro de Torre Farfán que describe de manera elogiosa la catedral de Sevilla. Este texto aparece con imágenes de alzados y plantas, pretendiendo así dar mayor publicidad a unas formas avaladas por la autoridad del autor ${ }^{43}$. La obra puede considerarse como otro ejercicio reivindicativo más de la arquitectura gótica en pleno barroco, esta vez desde círculos ajenos a la disciplina, como vimos que también se hacía en otros lugares de Europa.

Efectos similares a los de Farfán tuvo el libro de Bravo de Acuña sobre la catedral de Toledo ${ }^{44}$, completado también con interesantes dibujos de Vergara el $\mathrm{Mozo}^{45}$. A estos textos habría que añadir el apartado del tratado de Simón García donde hace una alabanza de la catedral nueva de Salamanca, a la que define como obra gótica, trazada y ejecutada por los mejores arquitectos de aquel estilo. Como estaba realizada solo hasta la mitad de lo previsto cuando él entró a trabajar en su fábrica, aboga por su pronta conclusión, ateniéndose a la disposición original sin introducir novedades propias de la época, pues así fue aprobado en su día por la comisión técnica formada por los arquitectos de las catedrales de Toledo, Sevilla, León y Burgos. No obstante, para justificar su actualidad y perfección, ofrece con detalle sus medidas como fundamento de pro-

42 IBÍDEM, p. 75.

43 TORRE FARFÁN, F., Fiestas de la Santa Iglesia Metropolitana y Patriarcal de Sevilla, Sevilla, 1671.

44 BRAVO de ACUÑA, J., Libro de la fundación de la sancta iglesia de Toledo, sus grandeças, primaçia, dotaçiones y memorias, Toledo, 1604.

45 MARÍAS, F., "La memoria de la catedral de Toledo desde 1604: la descripción de Juan Bravo de Acuña y la planta y dibujos ceremoniales de Nicolás de Vergara el Mozo", Anuario del Departamento de $H^{a}$ y Teoría del Arte, v. 21, 2009, pp. 105-120. porción en el que se sustenta la belleza ${ }^{46}$. Algo similar hace Pedro Salazar al comparar en valor la seo toledana con el templo de Diana en Éfeso, una de las Siete Maravillas de la antigüedad, ejemplo de perfección numérica ${ }^{47}$.

Los tratados de estereotomía son otra fuente esencial para nuestro tema ${ }^{48}$. En los textos barrocos encontramos el repertorio de la arquitectura clásica, pero al lado hay también una antología de bóvedas de crucería y otros elementos de tradición gótica ${ }^{49}$. El primero conocido es el manuscrito de Ginés Martínez de Aranda ${ }^{50}$, probablemente redactado en los primeros años del siglo XVII. En realidad no aporta grandes novedades con respecto a la montea tardogótica, pero si lo traemos aquí no es solo por ser un tratado que en los albores del barroco sistematiza la estereotomía conocida hasta el momento, sino también porque uno de los ejemplares perteneció a José Simón de Churriguera, pasando después a otros familiares de la famosa saga, considerada como paradigma del barroco español ${ }^{51}$, prueba fehaciente de la vigencia de sus trazas todavía en pleno siglo XVIII.

De menor difusión, debido a la insularidad de su autor, pero de mayor interés para nosotros, es el manuscrito del mallorquín Joseph Gelabert ${ }^{52}$.

${ }_{46}$ GARCÍA, S., Op. cit., ff. 51v.-52v.

47 P. SALAZAR Y MENDOZA, Crónica del Gran Cardenal de España D. Pedro González de Mendoza, Toledo, 1625, p. 15, “...dieronle de largo quatrocientos y quatro pies,y de ancho dozientos y dos... Estas medidas tiene agora la yglesia, que no se ha mudado y son las que tuvo el templo de Diana en Efeso, que se fabrico sobre una laguna y fue una de las siete maravillas de el mundo".

48 La teoría de los tratados no siempre fue posible aplicarla en la práctica directamente, siendo necesaria una adaptación a la realidad concreta, pues las trazas no son representaciones, sino que actúan más bien como explicaciones funcionales. El tema lo trata TAÍN-GUZMÁN, M. y OTROS, “Stonecutter's literature and construction practice in Early Modern Gothic: the trancings for a rib vault at the Cathedral of Tui in Galicia”, en Construction History, 2012, vol. 27, pp. 1-2; TAÍN-GUZMÁN, M., "Las monteas en Galicia: propuesta de una tipología”, Goya, n² 297, pp. 339-355.

49 CALVO LÓPEZ, J., "Estereotomía de la piedra", en I Máster de Restauración del Patrimonio Histórico, Murcia, 2005, p. 133.

50 MARTÍNEZ DE ARANDA, G., Cerramientos y trazas de montea, (Ms. Servicio Histórico del Ejército, Madrid. Ed. facsimilar Madrid, Servicio Histórico del Ejército CEHOPU, 1986).

51 CALVO LÓPEZ, J., "El manuscrito Cerramientos y trazas de montea, de Ginés Martínez de Aranda”, Archivo Español de Arte, n 325, 2009, p. 4.

52 GELABERT, J., Vertaderas traçes del art de picapedrer, de les quals sa poden aprofitar molt facilment tots los qui desitjen asser mestras aprimorats de dit art sols 
Dado que el autor justifica la validez de su texto para atajar la disparidad y arbitrariedad de opiniones existentes a la hora de ejecutar las trazas, nos está diciendo que sus propuestas quieren servir a la construcción que se estaban ejecutando en aquellos momentos; por lo tanto, el tratado no se plantea como una mera cuestión histórica, sino de interés para los maestros de obra contemporáneos. Prueba de ello es el cuidado que aplica para describir las formas de las piezas, plantillas, medidas, etc., lo que nos indica que la construcción de bóvedas de crucería era todavía algo vivo, aunque necesitaba una fundamentación técnica más allá de la trasmisión gremial $^{53}$. En cuanto al apartado teórico, muestra la intención de establecer una regla segura para los trabajos de estereotomía, conteniendo distintas soluciones, entre las que incluye las bóvedas de crucería; lo cual permite entender la tradición medieval a través de una fuente primaria, pero de la misma manera muestra la distorsión del gótico fuera de su tiempo. En cualquier caso, en Gelabert aparece un gótico ya contaminado con la preocupación moderna por el rigor geométrico y la exactitud de las medidas y proporciones similares a las canónicas ${ }^{54}$.

Situados en el siglo XVIII, comprobamos que todavía algunos tratados mantenían capítulos centrales para explicar el arte de la montea, en los que incluían trazas góticas. A principios de la centuria reseñamos la aportación de Vicente Tosca ${ }^{55}$, cuya voluminosa obra matemática contiene un notable apartado de estereotomía. Trata los consabidos cinco órdenes clásicos, pero también dedica un capítulo a otros, entre los que incluye el gótico, al cual califica de interesante e ingenioso, pero difícil de ejecutar, ya que exige grandes dosis de ingenio y habilidad, siguiendo así los mismos

sapien llegir y conoxer las cifras, 1653, estudiado por RABASA DÍAZ, E., El manuscrito de cantería de Joseph Gelabert, Madrid, 2012.

53 RABASA DÍAZ, E., "De l'art de picapedrer (1653) de Joseph Gelabert, un manuscrito sobre estereotomía que recoge tradiciones góticas y renacentistas", Actas del $V$ Congreso Nacional de $H^{a}$ de la Construcción, Madrid, 2007, pp. 752.

54 IBÍDEM, pp. 748; GAMBÚS SÁIZ, M., "De l'art de Picapedrer de Josep Gelabert: un testimonio literario de la arquitectura mallorquina del siglo XVII", Mayurqa, $\mathrm{n}^{\circ}$ 22, 2, 1989, p. 779.

55 VICENTE TOSCA, T., Compendio Mathemático en que se contienen todas las materias más principales de las ciencias que tratan de la cantidad. El tomo V está dedicado a Arquitectura civil, Montea y Cantería, Arquitectura Militar, Pirothecnia y Artillería, Valencia, 1707. criterios de valoración utilizados por Caramuel. Desde de su perspectiva matemática, por lo tanto mediatizada por el número y la proporción canónica, considera que la arquitectura gótica no es hermosa, porque no siempre lo que parece mejor al ingenio es más apacible al sentido. De esta manera, frente a lo que suele ser habitual en la mayoría de los teóricos, la encuentra más apta para el entendimiento que para la vista y el sentimiento, porque piensa que es necesaria una interpretación intelectual para entender las dificultades técnicas que salvan las estructuras góticas; no obstante, reconoce el mérito de estas obras que están concebidas conjugando la inteligencia con la fantasía, aunque entren en contradicción con las normas clásicas ${ }^{56}$. Cuando se ocupa del arte de la montea en su vertiente práctica, plantea dos problemas relacionados con nuestro tema. El primero trata la descripcion y fabrica de las bovedas con cruzeros de piedra ${ }^{57}$, explicando la mejor manera de hacer una cubierta sólida aunque liviana, pues aconseja el uso del ladrillo u otro material poco pesado para la plementería, adaptando la estructura medieval a soluciones más fáciles y baratas (fig. 3). En el segundo se ocupa sobre la manera de formar una bóveda con arcos cruzeros sobre qualquiera polígono, aunque advierte que ya no se estila semejante fábrica, pues pertenece más al orden Gothico, que a los otros cinco que están en uso, pero lo estudia porque le parece notable el artificio, poniendo como ejemplo el cimborrio de la catedral de Valen$\mathrm{cia}^{58}$. En este caso hace el análisis por interés histórico y reconocimiento de una técnica relevante de la arquitectura pasada, no como el problema anterior al que juzga propio del momento y le sugestiona por la aplicación.

El manuscrito de Juan de Portor y Castro, que parece más un cuaderno de trabajo de uso particular que un texto con interés teórico y pensado para su publicación, presenta una serie de cubiertas nervadas de diferente delineación y calidad técnica ${ }^{59}$. Esta circunstancia hace pensar que no están todos realizados por la misma mano y que hay aportaciones de diversos origenes; en cualquier caso, lo que ahora nos interesa

\footnotetext{
56 LEÓN TELLO, F.J., "Introducción a la teoría de la arquitectura del P. Tosca”, Revista de Ideas Estéticas, n 140 , p. 44.

57 VICENTE TOSCA, T., Op. cit, fol. 226.

58 Ibidem, fol. 227.

59 PORTOR Y CASTRO, J. de, Cuaderno de Arquitectura,
} 1708-19. 


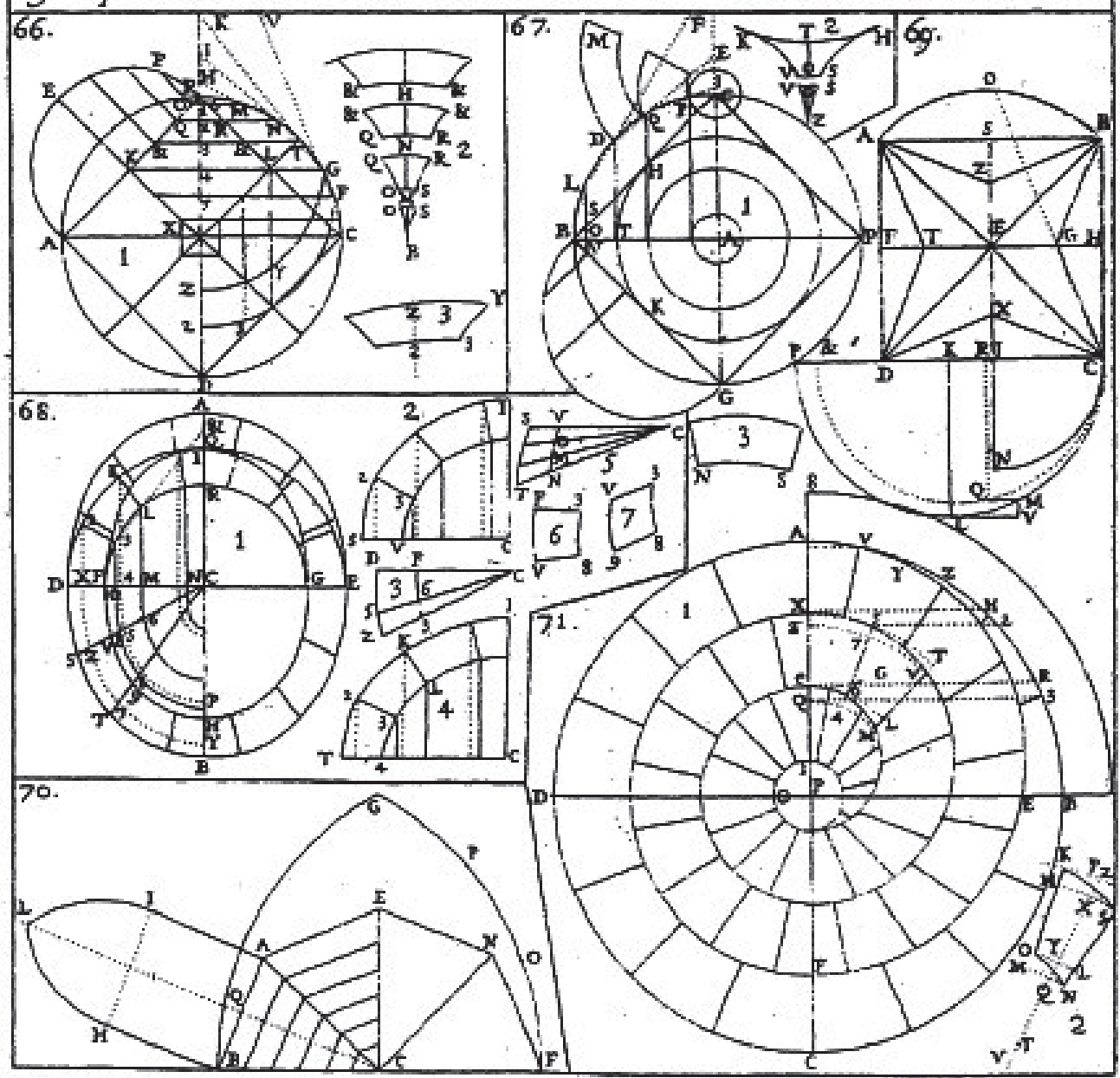

Fig. 3. Bóveda con cruceros ( $\mathrm{n}^{\circ}$ 69, arriba derecha) y Bóveda con cruceros sobre cualquier polígono ( $\mathrm{n}^{\circ}$ 70, abajo izquierda), fol. $232 \mathrm{r}$. Compendio Mathemático, Tomás Vicente Tosca.

es constatar que si los recogió en su cuaderno de trabajo fue por su utilidad particular en aquel momento ${ }^{60}$. Los dibujos de las bóvedas de crucería, al contrario del resto, no están explicados y presentan una delineación diferente, por lo que pudiera haberlos recogido de otros cuadernos similares, hoy perdidos, siendo unos originales y otros copiados. Dos de ellos representan, con detalle y buena factura técnica, sendas bóvedas

60 BARBÉ-COQUELIN, G., "Creatividad y sumisión al poder de la Iglesia: Juan de Portor y Castro y sus Cuadernos de Arquitectura manuscrito, un testimonio ejemplar (1708-1719)", en Arte, poder y sociedad en la España de los siglos XV a XX, Madrid, 2008, pp. 63-70, CARVAJAL ALCAIDE, R., "Estructura y singularidad del Cuaderno de arquitectura de Juan de Portor y Castro (1708-1719)", Actas VII Congreso Nacional de Historia de la Construcción, Madrid, 2011, pp. 211-220. de crucería con combados que remiten al estilo de Vandelvira (fig. 4). Más adelante aparece una bóveda de crucería con terceletes, apenas un rasguño dibujado de manera muy simple; igual de sencilla es la representación de la cabecera de una iglesia cubierta con crucería, donde nos llama la atención la disposición de claves en mitad de los nervios, además de las situadas en los cruces; distribución que vemos en la bóveda barroca de la catedral de Astorga. Por último, queremos destacar que Portor copia de manera literal la bóveda poligonal con cruceros que vimos explicada por Tosca en su tratado, por lo que pensamos que la tomaría de allíb1.

\footnotetext{
61 El cuaderno de Portor se compara con el realizado por Francisco Sarela, véase, CARVAJAL ALCAIDE, R. y CORTÉS LÓPEZ, M. E., “Aportaciones gallegas para la
} 


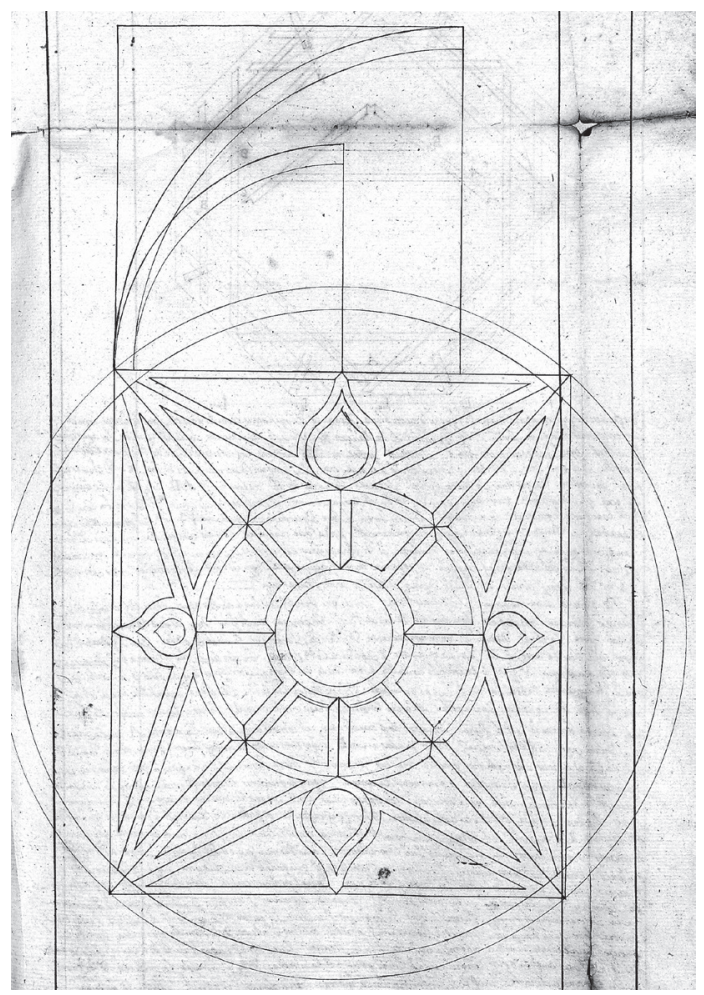

Fig. 4. Bóveda de crucería, fol. 89, Cuaderno de Arquitectura, Juan Portor.

Joseph Ribes realizó un manuscrito en el que despliega una colección de 40 bóvedas de crucería. Son de cierta complejidad geométrica, hasta alcanzar en unos casos las 17 claves $^{62}$. Algunos prototipos son ciertamente originales por la insólita delineación de sus nervios, resolviendo la bóveda con un intradós de superficie esférica a la manera de las obras tardogóticas del $\mathrm{XVI}^{63}$. Las inesperadas soluciones formales de estas bóvedas demuestran el interés de Ribes por la novedad y la invención a través de la investigación de geometrías inéditas, aunque fuera partiendo de cubiertas más propias de épocas pasadas. Su aportación enriquece el corpus teórico de la montea española y testimonia, una vez más, el interés intelectual por las bóvedas

historia del corte de la piedra en España: Los cuadernos de Juan Portor y Francisco Sarela", en Actas del VIII Congreso Nacional de Historia de la Construcción, Madrid, 2013, pp. 161-170

62 RIBES, J., Llibre de trassas de viax y muntea, 1708, ms. En la Biblioteca de Catalunya.

63 TELLIA, F., "El tratado de estereotomía de Joseph Ribes, 1708". Actas VII Congreso Nacional de $H^{a}$ de la Construcción, Madrid, 2012, pp. 1413-1420; ÍDEM, “Las bóvedas de crucería en el Llibre de trasas de viax y muntea de Joseph Ribes", Actas VIII Congreso Nacional $H^{a}$ de la Construcción, Madrid, 2013, pp. 1017-1025. góticas en pleno siglo XVIII ${ }^{64}$. Como el tratado es únicamente gráfico, sin texto explicativo alguno, nos hace pensar que Ribes quiso especular más que plantear soluciones prácticas, jugando con la geometría para proponer nuevas formas a los tradicionales dibujos de las crucerías con combados, pero con total despreocupación por su idoneidad o la oportunidad de su viabilidad constructiva (fig. 5).

Todavía a mediados de siglo Andrés Julián de Mazarrasa escribió un tratado en el que incluía un libro dedicado a los cortes de cantería $^{65}$, donde podemos ver algunos ejemplos que parecen también tomados directamente de Tosca, junto a otros que están ligados a la larga tradición de la buena cantería cántabra ${ }^{66}$.

La sorprendente vitalidad de la estereotomía en este siglo se debe tanto a la continuidad propia de la arquitectura española, como a una nueva reflexión de matiz historicista surgida en el contexto centroeuropeo, pues no debemos olvidar que más allá de nuestras fronteras sucedía algo similar ${ }^{67}$, como dejamos planteado al principio de este artículo al reseñar los principales ejemplos europeos como prólogo de los españoles. En cualquier caso, hemos registrado un repertorio suficiente para demostrar la preocupación teórica e intelectual que había sobre el tema, que a su vez evidencia el interés práctico de un gran número de maestros barrocos que seguían trabajando con bóvedas de crucería. Los artífices tenían que salvar las dificultades de la construcción de la época, que, como apunta el profesor Bonet, obedecía a problemas diferentes de los medievales, y que por ello se ha de analizar con presupuestos distin$\operatorname{tos}^{68}$, aunque es evidente que la elasticidad del sistema de nervaduras puede adaptarse a cualquier espacio y tipo de alzado $^{69}$, lo que también propició su uso.

${ }_{64}$ TELLIA, F., “Las bóvedas..., p. 1024.

${ }^{65}$ MAZARRASA, A. J. de, Tratado de Arquitectura, escrito entre 1750 y 1760 , compuesto de seis libros, uno de los cuales está dedicado a Montea y cortes de cantería.

${ }_{66}$ El tratado es analizado por MAZARRASA MOWINCKEL, O. y FERNÁNDEZ HERRERO, F., Mazarrasa. Maestros canteros y arquitectos de Trasmiera, León, 1988.

67 GÓMEZ MARTÍNEZ, J., Op. cit, p. 52.

${ }_{68}$ BONET CORREA, A., "Los tratados de cortes de piedra españoles en los siglos XVI, XVII y XVIII", Boletín de la Real Academia de Bellas Artes de S. Fernando, 1989, $n^{\circ}$ 69, pp. 29-62.

${ }^{69}$ RABASA DÍAZ, E., Forma y construcción en piedra..., p. 192. 

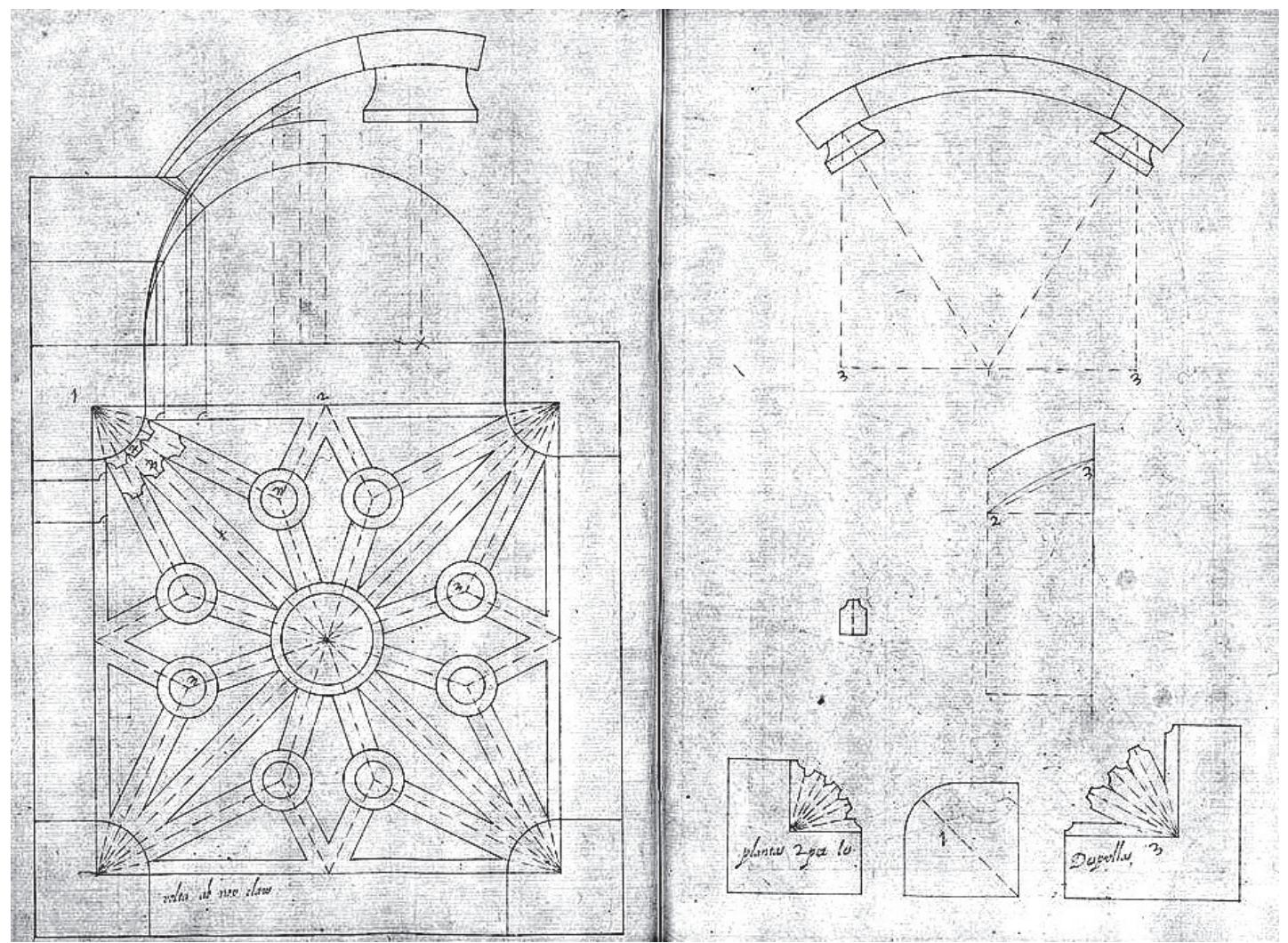

Fig. 5. Bóveda de crucería de nueve claves, Llibre de trassas de viaix y muntea, Joseph Ribes.

Al lado de toda esta variada tipología de literatura arquitectónica, también nos podríamos encontrar con diversos materiales, como apuntes, rasguños, trazas sueltas y cuadernos de trabajo de marcado carácter utilitario y uso privado. Presumimos que manuscritos de este tipo habría bastantes y que pasarían de mano en mano de los artífices hasta quedarse obsoletos y perderse con el paso del tiempo, razón por la cual han llegado muy pocos hasta nosotros. Sí conservamos el manuscrito de la familia Tornés, elaborado por distintas manos de dicha familia entre 1640 y 1743, que se abre con la planta de la iglesia de Sta. Eulalia Mayor (Jaca) en primera página, cubierta con bóvedas estrelladas, y más adelante dos trazas más de bóvedas de crucería de diseño original, probablemente utilizadas en obras realizadas por alguno de los Tornés ${ }^{70}$.

Otro ejemplo peculiar sería el recetario de Alonso de Guardia, escrito en los espacios en

70 Véase, JUAN GARCíA, N., Trazas y diseños. El manuscrito de la familia Tornés, su aportación al arte de la Edad Moderna y su vinculación con la tratadística arquitectónica, Zaragoza, 2013. blanco que dejaba un ejemplar del libro de Battista Pittoni Imprese di diversi principi, duchi, signori e d'altri personaggi et huomini illustri ${ }^{71}$, donde encontramos la explicación de una bóveda de crucería, aunque vista desde una concepción renacentista del corte de la piedra ${ }^{72}$.

De entre los textos escritos por personas ajenas a la construcción y destinados a la clase culta, destacamos el tratado de Jean-Charles della Faille, escrito en 1636 para impartir clases a los nobles madrileños en el Colegio Imperial de Madrid, en el que defiende la utilización de ciertas obras góticas en aras de encontrar ornamentos nuevos para las edificaciones del momento ${ }^{73}$.

71 Biblioteca Nacional, ER/4196, dado a conocer por MARÍAS, F., "Trazas, trazas, trazas: tipos y funciones del dibujo arquitectónico" en ARAMBURU ZABALA, M. A. (dir.), Juan de Herrera y su influencia, Santander, 1993, pp. 351-359.

72 RABASA DÍAZ, E., Forma y construcción en piedra..., p. 188.

73 FAILLE, J-C. della, Tratado de la Architectura, Biblioteca del Palacio Real, Ms. II/3729, citado por MARÍAS, F., "Gótico y neogótico en la Castilla del siglo XVI", en Le gothique de la Renaissance: actes des quatrièmes 
A la vista de la serie de referencias que hemos ido exponiendo, aunque lo hayamos hecho de manera sucinta por problemas de espacio, podemos llegar a una serie de conclusiones que confluyen en una indiscutible: las formas góticas seguían vivas en la práctica constructiva del barroco, siendo para ello decisiva la contribución de la literatura arquitectónica actuando desde diferentes frentes; y viceversa, pues la teoría y la práctica se retroalimentan para mantener de actualidad fórmulas tradicionales.

Aunque en España no se llegó a plantear la invención de órdenes góticos, ni a fundir lo gótico con lo griego para crear un nuevo estilo, como hicieron algunos tratadistas europeos, sí hubo ciertos teóricos que quisieron "ordenar" el gótico, es decir, encontrar esas reglas objetivas basadas en el número que de por sí otorgan un grado de perfección y belleza, como primer y decisivo paso para poder defender el gusto gótico. Pero, por otro lado, también hemos visto como conocidos arquitectos volvieron la vista hacia el medievo porque entendían que era una ayuda más para romper con la inercia clásica y poder superar la arquitectura encorsetada en reglas absolutas que coartaban la imaginación de los artífices, cuestión que podemos considerar como un objetivo primordial del barroco. Sería una contribución más a lo que Simón Marchán llama la disolución del clasicismo ${ }^{74}$.

Es cierto que la mayoría de la literatura especializada del barroco se preocupa sobre todo por mostrar el repertorio utilizado por la arquitectura renacentista y que a raíz de esto surgen valoraciones negativas y hasta hostiles hacia lo medieval, pero no sería justo olvidar el considerable número de escritos, nunca mayoritarios, que evalúan positivamente la tradición gótica. La nómina de autores vistos aquí -de origen, cronología y formación múltiples-, de manera consciente o inconsciente contribuyeron a la ruptura con la concepción arquitectónica heredada del renacimiento, basándose en ideas, motivaciones y objetivos distintos a los enarbolados por los arquitectos y promotores de la corriente dominante, que iba por derroteros formales muy distintos.

Rencontres d'architecture européenne, Paris, 12-16 juin 2007, París, 2011, pp. 153-154.

74 MARCHÁN, S., La disolución del clasicismo y la construcción de lo moderno, Salamanca, 2010, p. 43.
Hubo también intelectuales, cercanos a ciertos círculos de poder tradicionales, que elaboraron textos con alabanzas a edificios góticos de reconocida excelencia, que sirvieron para sustentar un gusto por lo gótico fuera de su tiempo, favoreciendo la comprensión de esas formas del pasado a un público que les interesaba tener cercano y que era proclive a aferrarse en la tradición. No podemos olvidar que en España la idea de lo gótico está relacionada para muchos teóricos políticos con la continuidad histórica, considerándose el reino visigodo cristiano como origen de la monarquía hispana, fundamentando en ello la legitimación tanto de la corona como de la noble$\mathrm{za}$, vencedoras en su momento de las huestes musulmanas. Surge así la consideración de la "antigüedad gótica" como autoridad política y eclesiástica, que tiene su correlato en el arte y la arquitectura, superando en ciertos ambientes a la antigüedad clásica como referencia, pues, no en vano, esta fue pagana y traída de fuera ${ }^{75}$.

Otros textos, de carácter práctico y valor técnico, decidieron ofrecer soluciones experimentadas a los maestros de obra que estaban construyendo entonces bóvedas de crucería, por medio de tratados de estereotomía que explicaban la manera de realizar con solvencia arcos y bóvedas que continuaban formas tradicionales, no queriendo que se perdiesen por considerarlas todavía válidas, aunque cada vez más alejadas de la corriente general.

En definitiva, estamos ante una interesante variante arquitectónica, contraria a la línea habitual de la época, sustentada tanto desde la ciencia como desde la experiencia, que manifiesta valores estéticos particulares de una parte de la sociedad del barroco, donde encontramos a teóricos, arquitectos, maestros de obra, promotores y público, los cuales no deben ser olvidados al hacer la historia de la arquitectura.

75 Sobre esta teoría véase, J. GÓMEZ MARTÍNEZ, op. cit., pp. 192-197; MARÍAS, F., "Memoria, correspondencia e integración de las artes en la Edad del Humanismo (siglos XVI-XVIII)", en Actas del XIV Congreso Nacional de Historia del Arte, Correspondencia e Integración de las Artes, vol. 1, Málaga, 2003, p. 73-84; 
